Ekspansi: Jurnal Ekonomi, Keuangan, Perbankan dan Akuntansi

ISSN (Online): 2580-7668 ISSN (Print): 2085-5230

Vol. 13, No. 2 (2021), Hal. 169 - 177

\title{
PENGARUH PDB DAN KURS RUPIAH-USD TERHADAP INVESTASI PORTOFOLIO ASING DI INDONESIA
}

\author{
Kurdiansyah $^{1}$, Iwan Wisandani ${ }^{2}$, Agus Ahmad Nasrulloh ${ }^{3}$ \\ 1,2,3 Program Studi Ekonomi Syariah, Fakultas Agama Islam, Universitas Siliwangi, \\ Tasikmalaya, Indonesia \\ Email Korespondensi: kurdiansyah314@gmail.com
}

\begin{abstract}
The influence of foreign investors on the financial sector in Indonesia is still very large. Therefore it is necessary to know the factors that affect the amount of Foreign Portfolio Investment in Indonesia. The aim of this study is to know the effect of the rupiah-usd exchange rate and GDP on Foreign Portfolio Investment in Indonesia in 2007Q1-2020Q4? The research method used is quantitative research. The data used is secondary data with documentation data collection techniques. The data analysis technique uses the Vectorautoregression (VAR) method with Eviews 9. The results of data analysis for the GDP variable (X1) only have a $0.4 \%$ effect on the fluctuation of Foreign Portfolio Investment $(Y)$ in Indonesia and $X 1$ does not have a Granger causality with $Y$. While the Rp-USD exchange rate (X2) has an effect of 7.78\% on Fluctuations in Foreign Portfolio Investment (Y) and X1 have Granger causality with Y. And $91.8 \%$ of the variables that affect the fluctuation of Foreign Portfolio Investment are Foreign Portfolio Investment itself or other random variables. The conclusion of the study, GDP (X1) has an insignificant effect of $0.4 \%$ on Foreign Portfolio Investment in Indonesia (Y). The RpUSD exchange rate (X2) has an effect of $7.78 \%$ on Foreign Portfolio Investment in Indonesia (Y).
\end{abstract}

Keywords: GDP, Exchange Rate, Foreign Portfolio Investment

Abstrak: Pengaruh investor asing pada sektor finansial di Indonesia masih sangat besar. Karena itu perlu diketahui faktor yang mempengaruhi jumlah Investasi Portofolio Asing di Indonesia. tujuan pada penelitian ini adalah untuk mencari tahu pengaruh Kurs rupiah-usd dan PDB terhadap Investasi Portofolio Asing di Indonesia pada tahun 2007Q1-2020Q4?. Metode penelitian yang digunakan merupakan penelitian Kuantitatif. Data yang digunakan merupakan data sekunder dengan teknik pengumpulan data dokumentasi. Teknik analisis data menggunakan metode Vectorautoregression (VAR) dengan Eviews 9. Hasil analisis data untuk variabel PDB (X1) hanya memiliki pengaruh 0,4\% pada fluktuasi Investasi Portofolio Asing (Y) di Indonesia dan X1 tidak memiliki kausalitas Granger dengan Y. Sedangkan Kurs Rp-USD (X2) berpengaruh sebesar 7,78\% terhadap fluktuasi Investasi Portofolio Asing(Y) dan X1 memiliki kausalitas Granger dengan Y. Dan 91,8\% variabel yang mempengaruhi fluktuasi Investasi Portofolio Asing merupakan Investasi Portofolio Asing itu sendiri atau variabel acak lainnya. Kesimpulan penelitian, PDB (X1) memiliki pengaruh tidak signifikan sebesar 0,4\% terhadap Investasi Portofolio Asing di Indonesia (Y). Kurs Rp-USD (X2) berpengaruh sebesar 7,78\% terhadap Investasi Portofolio Asing di Indonesia (Y).

Kata Kunci: PDB, Kurs, Investasi Portoflio Asing

DOI: $10.35313 /$ ekspansi.v13i2.3456 


\section{PENDAHULUAN}

Indonesia memerlukan jumlah dana yang besar untuk melakukan pembangunan dan mengembangkan berbagai sektor untuk meningkatkan taraf hidup masyarakatnya. Tabungan domestik tidak dapat memenuhi kebutuhan investasi dalam negeri, karena itu diperlukan pembiayaan yang berasal dari luar negeri untuk memenuhi kebutuhan investasi agar pembangunan dan kegiatan perkembangan dapat terus dilakukan. Sumber pembiayan dari luar negeri dapat berupa investasi asing dan utang luar negeri.

Investasi asing terdiri dari investasi asing langsung dan investasi portofolio asing. Kedua investasi tersebut memiliki karakteristik berbeda. Investasi asing langsung merupakan investasi jangka panjang seperti pendirian sebuah perusahaan sehingga investor memiliki pengaruh kuat pada perusahaan tersebut sedangkan investasi portofolio asing merupakan investasi jangka pendek pada surat berharga sehingga investor cenderung tidak memiliki pengaruh pada pengambilan keputusan manajemen dari perusahaan yang saham/surat utang-nya dibeli.

Investasi portofolio dapat berupa surat-surat berharga yang dapat diperjualbelikan secara internasional, seperti saham, uang, obligasi, sertifikat deposito, dapat juga berupa rekening bank atau pinjaman. Selain produk-produk umum, investasi portofolio juga memiliki produk syariah. Diantaranya saham syariah yang merupakan emiten yang kegiatan usahanya memenuhi ketentuan tentang hukum syariah, sukuk yaitu surat berharga yang didasarkan pada transaksi atau akad syariah seperti sewa (ijarah), bagi hasil (mudharabah) dsb, dan produk syariah lainnya .

Berdasarkan pengamatan awal mengenai investasi portofolio asing di Indonesia menunjukan fluktuasi investasi portofolio asing di Indonesia. Hal tersebut dapat dilihat pada gambar 1.1. Investasi Portofolio Asing di Indonesia mengalami fluktuasi setiap tahunnya dengan nilai tertinggi satu dekade terakhir pada 2019 awal dan terendah pada awal 2020. Poin positif berarti asing menyalurkan dananya (inflow) kedalam instrumen investasi portofolio di Indonesia dan poin negatif berarti asing melakukan penarikan dana (outflow) atau menjual asset-asetnya berupa surat berharga dan lain-lain.

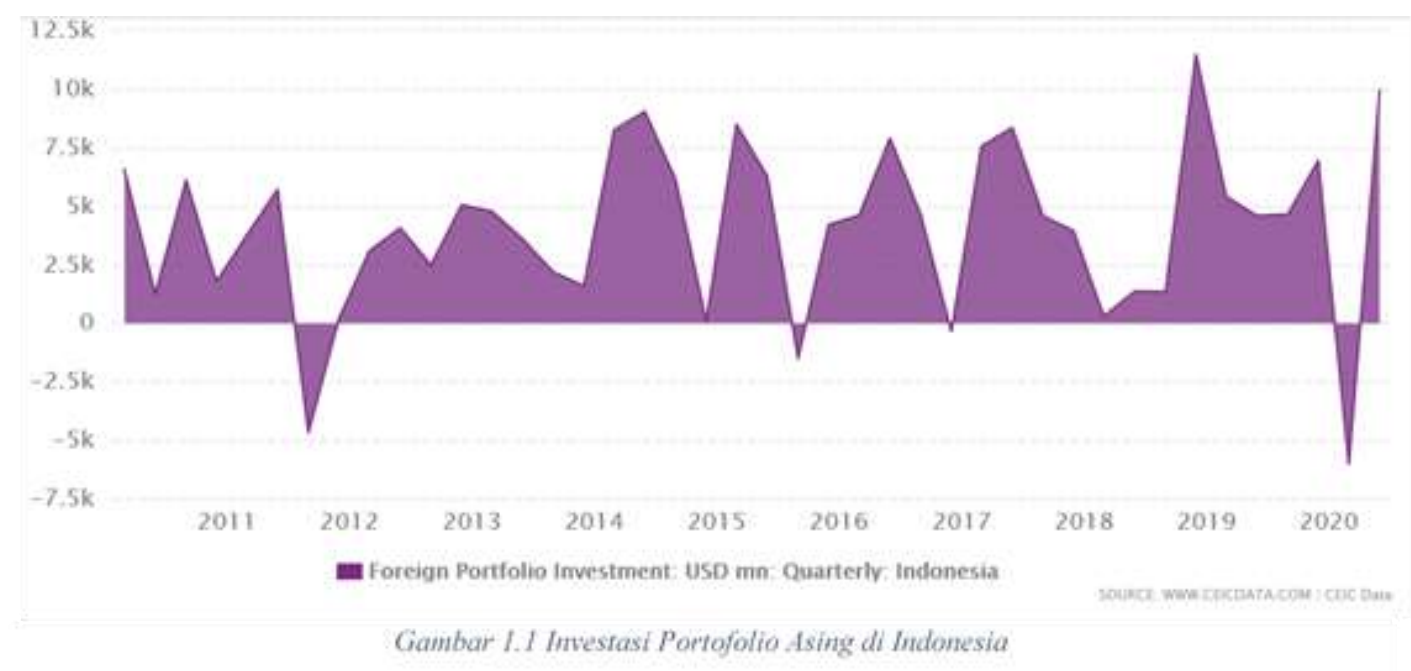

Sumber: CEIC Data 
Terjadi pergerakan yang tidak biasa pada tahun 2020 dimana awal tahun 2020 merupakan awal dari pandemi global Covid-19 yang menjangkiti seluruh dunia. Sehingga ekonomi dunia terguncang dan mata uang menjadi tidak stabil. Terlihat pada gambar 1.1 terjadi outflow besar pada kuartal pertama 2020 namun pada kuartal kedua terjadi inflow besar-besaran.

Keputusan investasi investor asing tentunya memiliki banyak faktor, faktor yang mempengaruhi keinginan investor individu atau instansi untuk melakukan investasi portofolio asing di suatu negara adalah tarif pajak atas bunga dan deviden, tingkat bunga, dan kurs mata uang. Perekonomian, tingkat inflasi dan iklim politik suatu negara juga dapat mempengaruhi aset portofolio asing. Menurut Halifah Hadi dalam penelitiannya, PDB dan nilai tukar merupakan hal yang berpengaruh terhadap Investasi portofolio asing.

Berdasarkan latar belakang masalah diatas, maka dapat diperoleh rumusan masalah sebagai berikut: 1) Bagaimana pengaruh kurs Rp-USD terhadap investasi portofolio asing secara parsial pada tahun 2007Q1-2020Q4 di Indonesia? 2) Bagaimana pengaruh PDB nominal terhadap investasi portofolio asing secara parsial pada tahun 2007Q1-2020Q4 di Indonesia?

Adapun tujuan dari penelitian ini untuk mengetahui pengaruh Untuk mengetahui pengaruh kurs Rp-USD terhadap investasi portofolio asing secara parsial pada tahun 2007Q1-2020Q4 di Indonesia. Dan untuk mengetahui pengaruh PDB nominal terhadap investasi portofolio asing secara parsial pada tahun 2007Q1-2020Q4 di Indonesia.

\section{TINJAUAN PUSTAKA}

\subsection{Produk Domestik Bruto}

Sadono Sukirno (2016:17) berpendapat bahwa PDB merupakan produk nasional yang diwujudkan oleh faktor-faktor produksi didalam negeri (milik warga negara dan orang asing) dalam suatu negara. Pada hakikatnya merupakan ukuran mengenai besarnya kemampuan suatu negara untuk menghasilkan barang dan jasa dalam suatu periode tertentu.

Sedangkan menurut Vina Sri Yuniarti (2016:158) PDB ialah nilai pasar dari semua barang dan jasa final dalam sebuah negara yang diproduksi pada suatu periode. Faktor produksi dalam PDB meliputi faktor produksi milik warga negaranya sendiri dan warga negara asing yang melakukan produksi di dalam wilayah negara tersebut.

Sadono Sukirno (2016:55) Pendapatan nasional memiliki beberapa cara perhitungan yaitu; PDB (Produk Domestik Bruto), dan PNB (Produk Nasional Bruto). Keduanya memiliki tujuan yang sama yaitu:

1) Menilai Prestasi Kegiatan Ekonomi

2) Menentukan Tingkat Pertumbuhan Ekonomi yang Dicapai

3) Memberikan Gambaran Mengenai Struktur Kegiatan Ekonomi

4) Data Asas untuk Membuat Ramalan dan Perencanaan 


\subsection{Kurs Mata Uang}

Adiwarman A. Karim (2007:157) Kurs mata uang menggambarkan tingkat harga pertukaran antara mata uang yang digunakan untuk perdagangan internasional, turisme, investasi internasional, ataupun aliran uang jangka pendek antarnegara yang melewati batas batas geografis dan hukum suatu negara.

Menurut Adiwarman A. Karim (2007:160) terdapat dua kebijakan Bank Sentral untuk mengatur sistem pertukaran mata uang di negaranya, yaitu:

1) Fixed Exchange Rate Regime

2) Flexible Exchange Rate Regime

Adiwarman A. Karim (2007:168) Dalam islam pemerintah tidak dapat mencampuri penawaran dan permintaan dalam pasar kecuali ada hal yang mengganggu keseimbangan itu sendiri. Karena itu nilai tukar dalam islam menganut sistem managed floating. Dalam hal ini terdapat dua skenario dalam pembahasan nilai tukar uang menurut islam, yaitu:

1) Perubahan Harga Terjadi Di Dalam Negeri

2) Perubahan Harga Terjadi Di Luar Negeri

\subsection{Investasi Portofolio Asing}

Dewi Cahyani Pangestu (2020:246) Investasi Portofolio Asing merupakan arus modal internasional berbentuk aset finansial, seperti obligasi, saham, dan commercial papers lainnya. Investor yang terlibat dalam kegiatan ini merupakan investor asing.

Alan C. Shapiro dan Peter Moles (2014:182) Investasi Portofolio Asing adalah pembelian aset finansial dengan jangka kematangan lebih dari satu tahun atau investasi jangka pendek dengan sekuritas yang berjangka kurang dari satu tahun.

Menurut Dewi Cahyani Pangestu (2020:255) untuk mendapatkan keuntungan yang lebih besar dan menekan risiko sekecil mungkin para manajer investasi besar melakukan diversifikasi dalam instrumen investasinya. Tidak hanya diversifikasi dalam produk namun dalam pasar yang ditanami modal investasinya, tidak hanya pasar dalam negeri tapi pasar luar negeri juga menjadi sasaran investasi para manajer investasi besar. Karena dengan melakukan investasi portofolio internasional seorang manajer investasi dapat memiliki peluang yang lebih besar dibandingkan dengan berinvestasi didalam negeri saja.

Alan C. Shapiro dan Peter Moles (2014:491) dalam berinvestasi secara internasional para manajer investasi perlu memperhatikan risiko-risiko yang kemungkinan dihadapi karena dalam berinvestasi di dalam dan di luar negeri tentu saja terdapat perbedaan. Berikut ini merupakan risiko apa saja yang kemungkinan dihadapi oleh manajer investasi dalam investasi portofolio internasional:

1) Kurs mata uang

2) Perubahan harga pasar

3) Politik, ekonomi, dan kejadian sosial

4) Kurangnya likuiditas

5) Terbatasnya informasi

6) Bergantung pada hukum asing 
7) Perbedaan operasi pasar

\section{METODE PENELITIAN}

Jenis penelitian yang digunakan dalam penelitian ini adalah asosiatif kausal yaitu penelitian yang bertujuan untuk menganalisis pengaruh antarvariabel dalam penelitian (Suliyanto, 2018:15). Lalu penelitian ini menggunakan pendekatan kuantitatif, yaitu metode penelitian yang memiliki landasan positivisme atau pandangan bahwa sebuah fenomena itu memiliki klasifikasi, terukur, dapat diamati, dan memiliki gejala sebab akibat. Analisis datanya bersifat kuantitatif/statistik dengan tujuan untuk menguji hipotesis yang sebelumnya telah ditetapkan (Sugiyono, 2012:13).

\subsection{Jenis dan Sumber Data.}

Sugiyono (2012:193) Pengumpulan data dalam sebuah penelitian dapat dilakukan dengan berbagai cara, berbagai sumber ataupun dari berbagai setting. Contoh data yang dikumpulkan berdasarkan setting adalah penelitian di laboratorium dengan metode experimen. Bila dilihat dari berbagai cara, dapat dilakukan dengan wawancara, kuisioner/angket, obeservasi/pengamatan dan dokumentasi. Dan bila dilihat dari sumber data, data terbagi kedalam dua jenis. Pertama sumber primer merupakan data langsung yang didapat pengumpul data dari sumber data. Kedua sumber sekunder merupakan pengumpulan data dengan cara melalui orang lain atau melalui dokumen untuk mendapatkan data, tidak mencari secara langsung ke sumber datanya. Pada penelitian ini digunakan cara pengumpulan data dokumentasi dengan sumber data sekunder.

\subsection{Uji Persyaratan Analisis}

Pada penelitian ini digunakan model Vector AutoRegression (VAR) yang pertama kali diperkenalkan oleh Christopher Sims pada 1980. VAR merupakan sebuah persamaan dengan $n$-variabel ( $n=j u m l a h)$ dimana masing-masing variabel dijelaskan dengan nilai kelambanannya (lag) tersendiri dan nilai masa lampau dan saat ini. Dengan menggunakan VAR data yang dimiliki harus dalam bentuk time series dan memiliki jumlah data yang besar (50 lebih data). Selain itu data time series yang dimiliki harus stasioner, jika data tidak stasioner hasil regresi yang didapatkan akan menjadi lancung (M. Firdaus, 2020:105).

1. Uji Stasionerisasi Data

Menurut Agus Widarjono (2005:354) suatu data dikatakan stasioner jika memenuhi tiga syarat, yaitu: rata-rata, varian dan kovarian dari data time series harus sama pada setiap waktu di tiap lag-nya (kelambanannya). Metode yang digunakan dalam penelitian untuk menguji apakah data stasioner atau tidak merupakan metode Augmented Dickey-Fuller (ADF).

2. Uji Stabilitas VAR

M. Firdaus (2020:211) Uji stabilitas VAR atau VAR stability condition check merupakan pengujian yang digunakan untuk melihat apakah VAR yang digunakan 
stabil atau tidak. Kestabilan VAR berpengaruh terhadap hasil analisis Variance Decomposition (VD). Saat VAR stabil maka VD yang dihasilkan dianggap valid.

\subsection{Teknik Analisis Data}

1. Penentuan Kelambanan

Menurut Agus Widarjono (2005:244) Langkah yang penting dalam menggunakan model VAR adalah penetuan jumlah kelambanan yang digunakan dalam model. Penentuan kelambanan yang optimal dapat ditentukan dengan informasi berdasarkan rumus yang telah diformulasikan yaitu salah satunya dengan Schwarz Information Criterion (SIC).

2. Uji Kausalitas Granger

M. Firdaus (2020:203) Pengujian kausalitas Granger merupakan pengujian hubungan sebab akibat dengan menggunakan F-tes untuk menguji apakah kelambanan informasi dalam variabel Y memiliki hubungan sebab akibat dengan variabel X. Uji ini digunakan untuk mengetahui apakah suatu variabel bebas meningkatkan kinerja forecasting dari variabel dependen.

3. Uji VDC (Variance Decomposition)

M. Firdaus (2020:217) Variance Decomposition merupakan metode untuk mengetahui bagaimana perubahan suatu variabel berdasarkan perubahan error variance yang dipengaruhi oleh variabel lainnya. Dengan metode ini peneliti dapat melihat kekuatan suatu variabel dalam mempengaruhi variabel lainnya dengan periode waktu yang panjang.

\section{HASIL DAN PEMBAHASAN}

\subsection{Hasil Penelitian}

\section{Uji Stasionerisasi Data}

Hasil uji stasioner pada ketiga variabel di tingkat level menunjukkan hanya variabel Investasi Portofolio Asing yang lolos uji stasioner. Sedangkan pada tingkat 1st difference menunjukkan bahwa ketiga variabel stasioner dikarenakan nilai ADF ketiga variabel lebih kecil dibandingkan nilai kritisnya. Maka ketiga variabel dapat dikatakan stasioner pada diferensi pertamanya (1st difference) sehingga proses analisis data akan menggunakan ketiga variabel dalam tingkat diferensi pertamanya (1st difference-nya).

\section{Uji Stabilitas VAR}

Berdasarkan hasil uji stabilitas VAR, model VAR dari ketiga variabel yang digunakan dalam penelitian memenuhi syarat kondisi stabil. Dikarenakan nilai modulus dari akar-akar polinomial dari model VAR memiliki nilai kurang dari satu.

\section{Penentuan Kelambanan}

Berdasarkan hasil analisis kelambanan optimal, didapatkan nilai Schwarz Information Criterion (SIC/SC) terkecil adalah 52.70178 yang merupakan lag satu. Maka dari itu lag yang paling optimum digunakan dalam penelitian ini menurut SIC merupakan satu. 


\section{Uji Kausalitas Granger}

Berdasarkan hasil uji kausalitas granger, dengan nilai $\alpha$ (signifikansi) 5\%/0,05 didapatkan bahwa hipotesis null yaitu Kurs Dollar tidak memiliki kausalitas granger terhadap Investasi Portofolio Asing ditolak dikarenakan nilai prob. $<\alpha(0,0344<0,05)$. Jadi yang diterima adalah hipotesis alternatif yaitu Kurs Dollar memiliki kausalitas granger terhadap Investasi Portofolio Asing.

Lalu hipotesis null Pertumbuhan PDB Riil tidak memiliki kausalitas granger terhadap Investasi Portofolio Asing di terima dikarenakan nilai prob. > $\alpha(0,8517>$ 0,05).

\section{Variance Decomposition}

Hasil uji variance decomposition menunjukan bahwa pada periode pertama Investasi Portofolio Asing tidak dipengaruhi oleh Kurs maupun PDB. Pada periode selanjutnya pengaruh Kurs meningkat pada fluktuasi nilai Investasi Portofolio Asing dan mencapai nilai konstan 7,78\% terhadap fluktuasi nilai Investasi Portofolio Asing pada periode ke-8. Sedangkan PDB hanya memiliki pengaruh 0,4\% pada fluktuasi nilai Investasi Portofolio Asing di Indonesia. Artinya 91,8\% variabel yang mempengaruhi fluktuasi Investasi Portofolio Asing merupakan Investasi Portofolio Asing itu sendiri atau variabel acak lainnya.

\subsection{Pembahasan Penelitian}

\section{Pengaruh Pertumbuhan PDB Riil terhadap Investasi Portofolio Asing}

Pertumbuhan PDB Riil tidak mencerminkan situasi berinvestasi pada suatu negara, sehingga investor tidak merespon berdasarkan Pertumbuhan PDB Riil dalam berinvestasi pada aset portofolio di Indonesia. Hal tersebut dikarenakan PDB dihitung berdasarkan performa sektor riil atau lapangan usaha yang ada di Indonesia, sedangkan sektor finansial memiliki mekanismenya tersendiri. Sekalipun perusahaan yang terdaftar di pasar modal merupakan bagian dari sektor riil tersebut, pasar modal hanyalah bagian dari aset portofolio dan keuntungan dari dividen yang diberikan perusahaan hanyalah setahun sekali. Karena itu respon para investor asing terhadap Pertumbuhan PDB Riil sangat kecil bahkan menurut uji kausalitas granger Pertumbuhan PDB Riil tidak memiliki pengaruh sebab-akibat dengan Investasi Portofolio Asing.

Hasil penelitian ini sesuai dengan hasil penelitian Halifah Hadi dkk. (2018) dimana Pertumbuhan PDB Riil memiliki pengaruh tidak signifikan pada Investasi Portofolio Asing di Indonesia dikarenakan peningkatan Pertumbuhan PDB Riil tidak diiringin dengan kebijakan yang memberikan kepastian hukum dalam berinvestasi. Namun tidak sejalan dengan penelitian Lusiana dan Idris (2020) dimana Pertumbuhan PDB Riil memiliki pengaruh terhadap Investasi Portofolio Asing di Indonesia. Karena pertumbuhan ekonomi yang dilihat dari Pertumbuhan PDB Riil dapat mencerminkan kestabilan produksi dan pengembalian investasi yang tinggi.

\section{Pengaruh Kurs Dollar terhadap Investasi Portofolio Asing}

Ketika nilai tukar rupiah terhadap dollar terapresiasi maka keuntungan yang didapat investor akan meningkat dikarenakan menambah margin dari keuntungan 
portofolio yang dimiliki investor tersebut. Namun berdasarkan hasil penelitian ini pengaruh kurs sangat kecil dikarenakan terdapat $91,8 \%$ pengaruh variabel acak lainnya yang mempengaruhi fluktuasi dari Investasi Portofolio Asing. Hal tersebut terjadi dikarenakan Kurs memiliki fluktuasi tersendiri sehingga investor asing tidak terlalu merespon pada pergerakan berdasarkan kurs. Selain itu kekuatan mata uang sebuah negara berpengaruh pada perekonomiannya terutama negara yang sedang berkembang seperti Indonesia dimana sektor produksinya masih banyak bergantung kepada luar negeri. Sehingga bank sentral dalam hal ini Bank Indonesia akan menjaga stabilitas rupiah. Terbukti pada saat Covid-19 mulai berdampak di Indonesia, sekalipun sektor riil terutama pariwisata masih terpuruk namun nilai rupiah dapat cepat pulih. Sehingga investor asing tidak terlalu merespon pada fluktuasi yang terjadi pada Kurs rupiah terhadap USD.

Hasil estimasi tersebut sesuai dengan hasil penelitian Kandir (2008) bahwa nilai tukar atau kurs berpengaruh pada nilai return portofolio. Namun tidak sesuai dengan penelitian Eliza (2013), penelitian tersebut mendapatkan bahwa kurs tidak signifikan pada Investasi Portofolio Asing dikarenakan pergerakan kurs terjadi dalam jangka pendek sehingga investor kurang merespon fluktuasi kurs.

\section{PENUTUP}

Kurs Rupiah terhadap Dollar memiliki kausalitas Granger terhadap Investasi Portofolio Asing. Kurs Rupiah terhadap Dollar memiliki pengaruh 7,78\% terhadap fluktuasi Investasi Portofolio Asing. PDB tidak memiliki kausalitas Granger terhadap Investasi Portofolio Asing. PDB memiliki pengaruh 0,4\% terhadap fluktuasi Investasi Portofolio Asing.

Dalam penelitian ini didapatkan bahwa fluktuasi Investasi Portofolio Asing 7,78\%nya diakibatkan oleh fluktuasi Kurs Dollar. Sekalipun responnya kecil namun tidak dapat dipungkiri bahwa Kurs Dollar menjadi salah satu hal yang mempengaruhi Investasi Portofolio Asing. Sehingga kedepannya Bank Indonesia perlu menjaga nilai rupiah agar tidak terdepresiasi terlalu dalam sekalipun saat terjadi krisis. Selain itu Bank Indonesia perlu menjaga kestabilan rupiah dengan kebijakannya agar investor asing memiliki kepercayaaan untuk menginvestasikan uangnya di aset finansial Indonesia.

\section{DAFTAR PUSTAKA}

A. Karim, Adiwarman. 2007. Ekonomi Makro Islam. Jakarta: Raja Grafindo.

Eliza, Messayu. 2013. "Analisis Pengaruh Variabel Makroekonomi Terhadap Investasi Asing Di Indonesia (Tahun 2000:1 - 2011:4)”. Malang: FEB Universitas Brawijaya.

Firdaus, M. 2020. Aplikasi Ekonometrika dengan E-Views, Stata, dan R. Bogor: IPB Press.

Pangestuti, Dewi Cahyani. 2020. Manajemen Keuangan Internasional. Yogyakarta: Deepublish. 
Hadi, Halifah et. al.. 2018. "Analisis Pengaruh Variabel Makroekonomi Dan Country Risk Terhadap Investasi Portofolio Asing Di Indonesia”. Padang: FE Universitas Negeri Padang.

Pratiwi, Lusiana dan Idris. 2020. "Analisis Determinan Investasi Portofolio Asing ( Studi Komparatif : Indonesia - China )". Padang: FE Universitas Negeri Padang. Ralhan, Mukesh. 2006. "Determinants Of Capital Flows: A Cross-Country Analysis". Victoria: Departmen Of Economics University Of Victoria.

Shapiro, Alan C. dan Peter Moles. 2014. International Financial Management. West Sussex: John Wiley \& Sons Ltd.

Sugiyono. 2012. Metode Penelitian Bisnis. Bandung: Alfabeta.

Sukirno, Sadono. MAKROEKONOMI Teori Pengantar Edisi Ketiga. Jakarta: Rajawali Pers.

Suliyanto. 2018. Metode Penelitian Bisnis untuk Skripsi, Tesis \& Disertasi. Yogyakarta: Andi Offset.

Widarjono, Agus. 2005. Ekonometrika: Teori Dan Aplikasi . Untuk Ekonomi Dan Bisnis. Yogyakarta: Ekonisia.

Yuniarti, Vina Sri . 2016. Ekonomi Makro Syariah. Bandung: Pustaka Setia. 